\title{
Prescription drug coverage satisfaction, cost-reducing behavior, and medication nonadherence among Medicare beneficiaries with type 2 diabetes
}

Qing He, MSc; Ciara L Silverman, PharmD; Chanhyun Park, PhD; Georgianne F Tiu, DrPH, MPH; and Boon Peng Ng, PhD

\section{What is already known about this subject}

- Medication nonadherence poses a considerable barrier to effective diabetes management and often results in poor health outcomes and increased health care utilization.

- Previous studies among individuals with diabetes have found that socioeconomic factors (eg, younger age, low income, lack of drug insurance coverage), comorbidities (eg, higher Charlson Comorbidity Index scores), and cost-related factors (eg, increased medication costs, out-of-pocket medication costs) are associated with a higher likelihood of medication nonadherence.

\section{ABSTRACT}

BACKGROUND: Medication nonadherence in individuals with type 2 diabetes can lead to poor glycemic control, resulting in increased risk for diabetes-related complications.

OBJECTIVE: To examine associations between factors (ie, drug coverage satisfaction and cost-reducing behavior) and

\section{What this study adds}

- This study adds new evidence and expands the current literature regarding factors that can potentially improve medication adherence by examining satisfaction of beneficiaries with the amount paid for medications, medications on formulary, and ability to find a pharmacy that accepts medication coverage, together with cost-reducing behavior, among Medicare beneficiaries with type 2 diabetes.

- Medicare beneficiaries with type 2 diabetes who were dissatisfied with the amount paid for medications and spent less on basic needs, such as food and heat, to save for medications were more likely to report medication nonadherence.

- Efforts to provide guidance and services to manage prescription medication costs and interventions to assist vulnerable groups who cut back on basic needs to save for medications are recommended to improve adherence.

medication nonadherence among Medicare beneficiaries with type 2 diabetes.

METHODS: We analyzed the 2016 Medicare Current Beneficiary Survey Public Use File for beneficiaries aged 65 years and older with reported type 2 diabetes ( $n=1,430$; weighted $n=5,846,943)$. Medicare beneficiaries were considered to have medication nonadherence if they reported skipping doses or

\section{Author affiliations}

Qing He, MSc, Department of Statistics and Data Science, University of Central Florida, Orlando. Ciara L Silverman, PharmD, Department of Pharmacy and Health Systems Sciences, School of Pharmacy, Northeastern University, Boston, MA. Chanhyun Park, PhD, Health Outcomes Division, College of Pharmacy, University of Texas at Austin. Georgianne F Tiu, DrPH, $\mathrm{MPH}$, Department of Health Management and Policy, University of Kentucky, Lexington. Boon Peng Ng, PhD, College of Nursing and Disability, Aging, and Technology Cluster, University of Central Florida, Orlando.

AUTHOR CORRESPONDENCE: Boon Peng Ng, boonpeng.ng@ucf.edu

J Manag Care Spec Pharm 2021;27(6):696-705

Copyright $@ 2021$, Academy of Managed Care Pharmacy. All rights reserved.

taking smaller doses than prescribed. A survey-weighted logistic model, adjusted for sociodemographics and comorbidities, was conducted to examine associations of drug coverage satisfaction and cost-reducing behavior with medication nonadherence.

RESULTS: Among Medicare beneficiaries aged 65 years and older with type 2 diabetes, $10.3 \%$ reported medication nonadherence. 
In the adjusted analysis, the risk for medication nonadherence was higher among those who were dissatisfied with the amount paid for medications $(O R=2.43 ; P=0.002)$ compared with those who were satisfied, and those who spent less on basic needs to save for medications were more likely to report medication nonadherence $(\mathrm{OR}=2.23$; $P=0.011$ ) than those who did not.

CONCLUSIONS: Our findings suggest that medication nonadherence among Medicare beneficiaries with type 2 diabetes is associated with dissatisfaction with the amount paid for medications and cost-reducing behavior. Interventions that lower medication costs for Medicare beneficiaries may help to improve medication adherence among this at-risk population.

More than 34 million Americans are diagnosed with diabetes, with type 2 diabetes accounting for approximately 90\%-95\% of total cases. ${ }^{1}$ Because of the chronic nature of the disease and associated complications, type 2 diabetes imposes a significant economic burden on individuals and the US health care system. In 2017, the total estimated cost of diabetes in the United States was $\$ 327$ billion from direct medical costs and costs associated with reduced productivity. ${ }^{2}$ On average, individuals with diabetes incur additional expenditures of about $\$ 9,600$ per year attributed to diabetes and overall medical expenditures 2.3 times higher than individuals without diabetes. ${ }^{2}$ Additionally, the annual out-of-pocket cost for Medicare beneficiaries with diabetes was, on average, approximately $\$ 2,528$, adjusted to 2020 US dollars. ${ }^{3}$

The high costs associated with diabetes treatment, along with other factors (eg, lack of insurance coverage and low sociodemographic status), leads to increased levels of medication nonadherence in individuals with diabetes. ${ }^{4-9}$ Medication nonadherence rates range from $9 \%-14 \%$ among individuals with diabetes, ${ }^{4-6}$ which poses a considerable barrier to effective diabetes management and often results in poor health outcomes and increased health care utilization. ${ }^{10}$ Individuals with poor glycemic control are at increased risk for long-term complications, such as neuropathy, retinopathy, cerebrovascular disease, nephropathy, and diabetic foot infection. ${ }^{11}$ These individuals also experience higher rates of emergency department visits and hospitalizations compared with those who do not report medication nonadherence,,$^{10,12}$ as well as loss of productivity and reduced quality of life. ${ }^{2}$

Many risk factors for medication nonadherence within the wider US population with diabetes have been examined in previous studies. In general, younger age, low income, lack of drug insurance coverage, and increased medication costs are associated with a higher likelihood of medication nonadherence among individuals with diabetes. ${ }^{6,7}$ However, fewer studies have focused specifically on the risk factors for medication nonadherence among older adults. Type 2 diabetes is highly prevalent in this group, affecting approximately $27 \%$ of Americans aged 65 years and older, ${ }^{13}$ so further research within this age demographic is needed. Additionally, the economic burden associated with diabetes is substantial for this at-risk population, since Medicare spent about $\$ 42$ billion on diabetes in 2016. Furthermore, Medicare beneficiaries with diabetes have significantly higher out-of-pocket costs than beneficiaries without diabetes. ${ }^{3,14}$

Several conceptual models have been developed to understand factors that can influence medication adherence or nonadherence. ${ }^{15,16}$ Existing empirical studies in older Americans with type 2 diabetes have assessed factors of medication nonadherence such as sociodemographic factors, chronic conditions, and cost-related factors. ${ }^{8,9,17}$ Adopting the conceptual framework developed by Piette et $\mathrm{al}_{,}{ }^{15}$ we examined the association between drug coverage satisfaction (ie, satisfaction with the amount paid for medications, medications on formulary, and ability to find a pharmacy that accepts medication coverage) and costreducing behavior (ie, spending less on basic needs to save for medications) with medication nonadherence.

We hypothesized that Medicare beneficiaries dissatisfied with drug coverage benefits and those that partake in cost-reducing behaviors would be more likely to be nonadherent to medications. Understanding how these factors contribute to medication nonadherence is imperative to identifying effective and feasible interventions to mitigate these barriers for this at-risk population. Therefore, our study aimed to evaluate the association between (1) drug coverage satisfaction and (2) cost-reducing behaviors with medication nonadherence among Medicare beneficiaries with type 2 diabetes, using a nationally representative sample.

\section{Methods}

\section{DATA}

We used the 2016 Medicare Current Beneficiary Survey Public Use File (MCBS PUF) for this study. The MCBS PUF is a publicly accessible version of the MCBS and includes only community-dwelling Medicare beneficiaries..$^{18}$ The MCBS is representative of the Medicare population with the sampling technique that is described elsewhere. ${ }^{19}$ The dataset contains beneficiary sociodemographic characteristics, 
health conditions, utilization of and satisfaction with health care services, and medication-related data.

\section{STUDY POPULATION}

Our study population included Medicare beneficiaries aged 65 years and older with reported type 2 diabetes $(\mathrm{N}=1,430)$. Medicare beneficiaries were asked whether a doctor had told them they had diabetes. Those who indicated having diabetes were then asked the type of diabetes they had (Supplementary Table 1, available in online article).

\section{MEASURES}

Dependent Variable. The dependent variable was medication nonadherence, which was measured by 2 questions concerning beneficiary nonadherence behavior over the past 12 months (Supplementary Table 1): (1) "Have you often, sometimes, or never skipped doses to make the medicine last longer?" and (2) "Have you often, sometimes, or never taken smaller doses than prescribed of a medicine to make the medicine last longer?"

Similar measures and algorithms have been used by previous work to determine medication nonadherence. ${ }^{20}$ We constructed a binary indicator of medication nonadherence with the value of 1 for those who answered "often" or "sometimes" on either 1 of those 2 questions and 0 for those who answered "never" on both questions. Additionally, to ensure the robustness of our analysis, since we had combined both questions to measure medication nonadherence, 2 individual binary dependent variables were constructed and analyzed: one for skipping doses (ie, 1=often or sometimes skipped doses; $0=$ never skipped doses) and the other for taking smaller doses (ie, $1=$ often or sometimes taken smaller doses; $0=$ never taken smaller doses).

Independent Variables. The independent variables included beneficiaries' prescription drug insurance coverage, prescription drug coverage satisfaction, cost-reducing behavior, and sociodemographic and health-related covariates.

Prescription drug insurance coverage. For each of the 3 prescription insurance plans (ie, Medicare Advantage plans, private plans, and Medicare Part D plans), we created a binary variable to reflect whether beneficiaries had that specific plan to cover prescription medications. The variable for Medicare Advantage plans included beneficiaries who enrolled in Medicare Advantage (or Part C) plans that covered prescription medications. The variable for private plans included beneficiaries who were identified to have prescription coverage based on employer-sponsored insurance (ESI), self-purchased insurance, or ESI and selfpurchased insurance. The variable for Part D plans included beneficiaries who enrolled in Original Medicare (or Part B) or Medicare Advantage that did not have prescription coverage.

Prescription drug coverage satisfaction. Drug insurance coverage satisfaction was measured by 3 variables: satisfaction with the amount paid for medications, satisfaction with the medications on formulary, and satisfaction with finding a pharmacy that accepted medication coverage. All 3 questions were originally measured on a 4-point Likert scale in the survey. To ensure a reasonable sample size, responses were dichotomized into 2 categories: $1=$ dissatisfied/very dissatisfied; $0=$ satisfied/very satisfied.

Cost-reducing behavior. Beneficiaries were asked whether they ever spent less on other basic needs, such as food and heat, to save for medications in a 3-level ordinal option, including "never," "sometimes," and "often." Responses of "never" were recoded as 0 and "often/sometimes" were recoded as 1 .

Sociodemographic and health-related covariates. The following sociodemographic covariates were included in the analysis: age (65-74, $\geq 75$ ); sex (male, female); race (White, Black, Hispanic, and Other); marital status (married, widowed, divorced/separated, and never married); education level (<high school, high school, and $>$ high school); income $(<\$ 25,000, \geq \$ 25,000)$; and residing area (metro, non-metro). We also included several health-related covariates: general health status (excellent/very good, good, and fair/poor); number of reported chronic conditions ( $\leq 1$ condition, 2 to 3 conditions, and 4 or more conditions); and physical/functional limitations (no functional limitations, instrumental activities of daily living [IADLs] only, 1 to 2 activities of daily living [ADLs], and 3 or more ADLs).

\section{STATISTICAL ANALYSES}

We examined the extent to which sociodemographic and health-related characteristics, as well as prescription drug coverage plans, differed by medication nonadherence using cross-tabulations and Wald chi-square tests. A multivariable logistic regression model, adjusted for sociodemographic and health-related characteristics, was used to examine the association between medication nonadherence and factors such as prescription drug coverage satisfaction and costreducing behavior. The descriptive and logistic regression results were weighted to represent the Medicare population using survey weights provided in the MCBS PUF data. All analyses were conducted by using SAS version 9.4 (SAS Institute), and the level of significance was at $\mathrm{P}<0.05$.

\section{Results}

Table 1 shows the sociodemographic characteristics and prescription drug coverage plans of the study sample by 


\section{TABLE 1}

Characteristics of Medicare Beneficiaries Aged $\geq 65$ Years With Reported Type 2 Diabetes, By Medication Nonadherence

\begin{tabular}{|c|c|c|c|c|}
\hline Variable & Total & $\begin{array}{c}\text { Medication } \\
\text { adherence }\end{array}$ & $\begin{array}{c}\text { Medication } \\
\text { nonadherence }\end{array}$ & $P$ value \\
\hline Unweighted, n & 1,430 & 1,307 & 123 & \\
\hline Weighted, n & $5,846,943$ & $5,244,202$ & 602,741 & \\
\hline Overall (weighted \%) & 100 & 89.7 & 10.3 & \\
\hline \multicolumn{5}{|c|}{ Sociodemographic characteristics } \\
\hline \multicolumn{4}{|l|}{ Age group } & $<0.001$ \\
\hline $65-74$ years & 59.5 & 57.4 & 77.8 & \\
\hline$\geq 75$ years & 40.5 & 42.6 & 22.2 & \\
\hline \multicolumn{4}{|l|}{ Sex } & 0.030 \\
\hline Female & 54.0 & 52.8 & 64.6 & \\
\hline Male & 46.0 & 47.2 & 35.4 & \\
\hline \multicolumn{4}{|l|}{ Race/ethnicity } & 0.863 \\
\hline White & 69.1 & 69.5 & 66.4 & \\
\hline Black & 11.0 & 10.8 & 12.6 & \\
\hline Hispanic & 12.4 & 12.5 & 11.2 & \\
\hline Other & 7.5 & 7.2 & 9.9 & \\
\hline \multicolumn{4}{|l|}{ Marital status } & 0.114 \\
\hline Married & 56.3 & 57.6 & 44.9 & \\
\hline Widowed & 24.1 & 24.1 & 24.6 & \\
\hline Divorced/separated & 14.0 & 13.1 & 21.8 & \\
\hline Never married & 5.6 & 5.2 & 8.7 & \\
\hline \multicolumn{4}{|l|}{ Education } & 0.606 \\
\hline Less than high school & 21.6 & 21.8 & 20.3 & \\
\hline High school or vocational & 34.4 & 33.8 & 39.8 & \\
\hline More than high school & 44.0 & 44.4 & 39.9 & \\
\hline \multicolumn{4}{|l|}{ Income } & 0.557 \\
\hline$<\$ 25,000$ & 40.2 & 39.8 & 43.0 & \\
\hline$\geq \$ 25,000$ & 59.8 & 60.2 & 57.0 & \\
\hline \multicolumn{4}{|l|}{ Residing area } & 0.338 \\
\hline Non-metro area & 21.1 & 21.4 & 18.1 & \\
\hline Metro & 78.9 & 78.6 & 81.9 & \\
\hline \multicolumn{5}{|l|}{ Comorbidities and health status } \\
\hline \multicolumn{4}{|l|}{ Number of chronic conditions } & 0.178 \\
\hline $0-1$ & 15.1 & 15.7 & 10.5 & \\
\hline $2-3$ & 64.2 & 64.1 & 64.5 & \\
\hline$\geq 4$ & 20.7 & 20.2 & 25.0 & \\
\hline
\end{tabular}

continued on next page medication nonadherence status. Among Medicare beneficiaries with type 2 diabetes in our study population, $10.3 \%$ (representing an estimated 600,000 Medicare beneficiaries) reported medication nonadherence. Compared with Medicare beneficiaries who adhered to medication, those with medication nonadherence were younger (aged $65-74$ years; $77.8 \%$ vs. 57.4\%; $\mathrm{P}<0.001)$ and more female beneficiaries $(64.6 \%$ vs. $52.8 \%$; $P=0.030)$. Many of them had poorer health status than those who adhered to medication. For example, higher proportions of beneficiaries with medication nonadherence had multiple ADL limitations ( $\geq 3$ ADLs; $18.5 \%$ vs. $12.6 \%$; $\mathrm{P}=0.006)$ and fair/poor general health status $(42.0 \%$ vs. $29.0 \% ; P=0.004)$.

With regards to the prescription insurance plans, $56.7 \%, 89.6 \%$, and $1.2 \%$ reported having no Medicare Advantage plans, no private plans, and no Part D among Medicare beneficiaries with medication nonadherence vs $50.1 \%, 89.1 \%$, and $4.2 \%$ among those who adhered to medication (Table 1). In Medicare Advantage plans and private plans, there was no significant difference observed in the proportions of beneficiaries with and without medication nonadherence. However, the difference in the proportions of beneficiaries with and without medication nonadherence was significant $(\mathrm{P}=0.017)$ among those with Part D coverage. This was an unadjusted analysis, and the small difference likely provided no clinical or practical significance.

Results from the multivariable logistic regression analysis are summarized in Table 2. Compared with Medicare beneficiaries aged 75 years and older, younger beneficiaries (aged 65-74 years) were more likely to report medication nonadherence (odds ratio $[\mathrm{OR}]=2.73 ; 95 \%$ $\mathrm{CI}=1.57-4.74)$. Beneficiaries who were divorced/separated were more likely 


\begin{tabular}{|c|c|c|c|c|}
\hline TABLE 1 & $\begin{array}{l}\text { ics of } \\
\text { eport } \\
\text { ce (co }\end{array}$ & $\begin{array}{l}\text { care Benef } \\
\text { pe } 2 \text { Diabe } \\
\text { ed) }\end{array}$ & $\begin{array}{l}\text { ciaries Aged } \\
\text { es, By Medic }\end{array}$ & \\
\hline Variable & Total & $\begin{array}{c}\text { Medication } \\
\text { adherence }\end{array}$ & $\begin{array}{c}\text { Medication } \\
\text { nonadherence }\end{array}$ & $P$ value \\
\hline Comorbidities and hea & & & & \\
\hline ADL limitations & & & & 0.006 \\
\hline No limitations & 51.0 & 53.0 & 34.0 & \\
\hline Only IADLs limited & 11.8 & 10.9 & 19.4 & \\
\hline 1-2 ADLs limited & 24.0 & 23.5 & 28.1 & \\
\hline$\geq 3$ ADLs limited & 13.2 & 12.6 & 18.5 & \\
\hline General health status & & & & 0.004 \\
\hline Excellent/very good & 33.1 & 34.7 & 18.5 & \\
\hline Good & 36.6 & 36.3 & 39.4 & \\
\hline Fair/poor & 30.4 & 29.0 & 42.0 & \\
\hline Drug coverage & & & & \\
\hline Medicare Advantage & & & & 0.218 \\
\hline No & 50.8 & 50.1 & 56.7 & \\
\hline Yes & 49.2 & 49.9 & 43.3 & \\
\hline Private plan coverage & & & & 0.864 \\
\hline No & 89.1 & 89.1 & 89.6 & \\
\hline Yes & 10.9 & 10.9 & 10.4 & \\
\hline Part D plan coverage & & & & 0.017 \\
\hline No & 3.9 & 4.2 & 1.2 & \\
\hline Yes & 96.1 & 95.8 & 98.8 & \\
\hline Prescription drug insu & ction & & & \\
\hline Dissatisfaction: the ar & or medi & & & $<0.001$ \\
\hline No & 73.1 & 76.1 & 46.2 & \\
\hline Yes & 26.9 & 23.9 & 53.8 & \\
\hline Dissatisfaction: the m & formu & & & $<0.001$ \\
\hline No & 84.9 & 87.4 & 63.5 & \\
\hline Yes & 15.1 & 12.6 & 36.5 & \\
\hline Dissatisfaction: find a & hat acce & nedication cc & erage & 0.054 \\
\hline No & 98.5 & 99.0 & 94.1 & \\
\hline Yes & 1.5 & 1.0 & 5.9 & \\
\hline Cost-reducing behavio & & & & \\
\hline Ever spent less on ba & ave for & ations? & & $<0.001$ \\
\hline No & 90.3 & 92.3 & 72.9 & \\
\hline Yes & 9.7 & 7.7 & 27.1 & \\
\hline
\end{tabular}

to report medication nonadherence $(\mathrm{OR}=2.10 ; 95 \% \mathrm{CI}=1.12-3.95)$, compared with those who were married. Dissatisfaction with the amount paid for medication was associated with a higher likelihood of medication nonadherence $(\mathrm{OR}=2.43 ; 95 \% \mathrm{CI}=1.41-4.18)$. Although not statistically significant, those that were dissatisfied with medications on formulary and ability to find a pharmacy that accepted medication coverage reported higher odds of medication nonadherence. Finally, having spent less on basic needs to save for medications was associated with a higher likelihood of medication nonadherence $(\mathrm{OR}=2.23$; 95\% CI $=1.21-4.10$ ).

To assess whether the multivariable logistic regression results were sensitive to the measure of the dependent variable, models with the dependent variable measured by either skipping doses or taking smaller doses were examined separately. Results from these 2 models (Supplementary Table 2, available in online article) were consistent with the main model in general. The positive or negative associations of the key factors of interest (ie, drug coverage satisfaction and cost-reducing behavior) with medication nonadherence remained the same, except that not all of the same factors were significant for the 3 models.

\section{Discussion}

Adverse effects of poor medication adherence on health outcomes are well established. Previous studies have linked medication nonadherence to a higher risk of diabetic complications, ${ }^{21}$ increased health care utilization ${ }^{10}$ and an even higher risk of all-cause mortality. ${ }^{22}$ As a result, it is imperative to understand the risk factors for medication nonadherence in individuals with diabetes, especially factors that can be improved, reduced, or modified. 


\section{TABLE 2 Survey-Weighted Logit Model to Predict Factors Associated With Medication Nonadherence Among Medicare Beneficiaries Aged $\geq 65$ Years With Reported Type 2 Diabetes}

\begin{tabular}{|c|c|c|c|}
\hline Variable & OR & $95 \% \mathrm{Cl}$ & $P$ value \\
\hline \multicolumn{4}{|c|}{ Sociodemographic characteristics } \\
\hline \multicolumn{4}{|l|}{ Age group } \\
\hline $65-74$ years & 2.73 & $1.57-4.74$ & $<0.001$ \\
\hline$\geq 75$ years & Ref & & \\
\hline \multicolumn{4}{|l|}{ Sex } \\
\hline Female & Ref & & \\
\hline Male & 0.84 & $0.50-1.43$ & 0.523 \\
\hline \multicolumn{4}{|l|}{ Race/ethnicity } \\
\hline White & Ref & & \\
\hline Black & 1.06 & $0.51-2.22$ & 0.867 \\
\hline Hispanic & 0.78 & $0.34-1.80$ & 0.557 \\
\hline Other & 1.42 & $0.53-3.79$ & 0.477 \\
\hline \multicolumn{4}{|l|}{ Marital status } \\
\hline Married & Ref & & \\
\hline Widowed & 1.59 & $0.81-3.13$ & 0.178 \\
\hline Divorced/separated & 2.10 & $1.12-3.95$ & 0.022 \\
\hline Never married & 1.88 & $0.68-5.19$ & 0.218 \\
\hline \multicolumn{4}{|l|}{ Education } \\
\hline Less than high school & Ref & & \\
\hline High school or vocational & 0.95 & $0.44-2.03$ & 0.885 \\
\hline More than high school & 0.92 & $0.47-1.82$ & 0.811 \\
\hline \multicolumn{4}{|l|}{ Income } \\
\hline$<\$ 25,000$ & 0.90 & $0.55-1.46$ & 0.654 \\
\hline$\geq \$ 25,000$ & Ref & & \\
\hline \multicolumn{4}{|l|}{ Residing area } \\
\hline Non-metro area & 0.80 & $0.48-1.33$ & 0.380 \\
\hline Metro & Ref & & \\
\hline \multicolumn{4}{|c|}{ Comorbidities and health status } \\
\hline \multicolumn{4}{|l|}{ Number of chronic conditions } \\
\hline $0-1$ & Ref & & \\
\hline $2-3$ & 1.44 & $0.71-2.91$ & 0.305 \\
\hline$\geq 4$ & 1.32 & $0.56-3.12$ & 0.529 \\
\hline \multicolumn{4}{|l|}{ ADL limitations } \\
\hline No limitations & Ref & & \\
\hline Only IADLs limited & 1.84 & $0.84-4.03$ & 0.127 \\
\hline 1-2 ADLs limited & 1.34 & $0.77-2.35$ & 0.298 \\
\hline$\geq 3$ ADLs limited & 1.47 & $0.65-3.34$ & 0.357 \\
\hline
\end{tabular}

We found that approximately $10 \%$ of Medicare beneficiaries aged 65 years and older with type 2 diabetes reported skipping doses or taking smaller doses than prescribed, which is consistent with the proportion of medication nonadherence reported in previous studies $(9 \%-14 \%))^{4-6}$ We also found that more than half of beneficiaries with medication nonadherence were dissatisfied with the amount paid for medications, and more than a quarter reported spending less on basic needs to save for medications. Both factors were significantly associated with a higher likelihood of medication nonadherence. In addition, our study identified that medication nonadherence among beneficiaries with type 2 diabetes was associated with demographic characteristics, such as younger age (65-74 years) and being divorced/separated. These findings highlight the need to assist older adults at risk of medication nonadherence to manage their prescription medication expenditures and advocate for programs (eg, zero copayment programs ${ }^{23}$ ) that can improve adherence for this at-risk population.

Results from our study illustrate that dissatisfaction with the amount paid for medications was associated with a higher likelihood of medication nonadherence among Medicare beneficiaries with type 2 diabetes. This finding is consistent with previous studies. Zhang et al examined risk factors associated with medication nonadherence (measured by "Sometimes people delay taking medication or filling prescriptions because of the cost") for the US population aged 50 years and older with diabetes using the 2010 Health and Retirement Study and found that high out-of-pocket (OOP) cost was significantly associated with medication nonadherence. ${ }^{6}$

Similarly, a study examined determinants of noninsulin antidiabetic drug adherence (defined as medication possession ratio $\geq 0.8$ ) from a large pharmacy claims database and found that high OOP cost was negatively associated with adherence. ${ }^{7}$ The study reported that the antidiabetic drug adherence decreased by $11 \%$ for an increase of $\$ 15$ in OOP cost per month.

Individuals with diabetes experience heightened financial burden because of high OOP costs associated with their diabetes medication regimen, as well as management of comorbid conditions, compared with individuals without diabetes. ${ }^{24}$ The average list price of insulin rose over $300 \%$ between 2002 and 2013, and the price is not likely to decline due to a lack of biosimilar competition and complex pricing mechanisms for insulin..$^{25}$ The increasing cost of insulin, in addition to other OOP costs incurred by individuals with diabetes, such as oral and noninsulin injectable antihyperglycemic agents and glucose monitoring tools (ie, test strips, lancets), can amount to a significant financial strain. Costly OOP expenses, combined with the high 


\section{TABLE 2}

\section{Survey-Weighted Logit Model to Predict Factors Associated With Medication Nonadherence Among Medicare Beneficiaries Aged $\geq 65$ Years With Reported Type 2 Diabetes (continued)}

\begin{tabular}{l|c|c|c}
\hline Variable & OR & $95 \% \mathrm{Cl}$ & P value \\
\hline Comorbidities and health status \\
\hline
\end{tabular}

\begin{tabular}{l|c|c|c}
\hline \multicolumn{5}{|l}{ General health status } \\
\hline Excellent/very good & Ref & & \\
\hline Good & 1.39 & $0.68-2.86$ & 0.360 \\
\hline Fair/poor & 1.33 & $0.59-2.95$ & 0.488 \\
\hline Drug coverage & & & \\
\hline
\end{tabular}

Medicare Advantage plan coverage

\begin{tabular}{l|c|c|c}
\hline No & Ref & & \\
\hline Yes & 0.89 & $0.53-1.47$ & 0.637 \\
\hline \multicolumn{3}{l|}{ Private plan coverage } & \\
\hline No & Ref & & 0.915 \\
\hline Yes & 1.05 & $0.46-2.39$ & \\
\hline Part D plan coverage & Ref & \\
\hline No & 3.92 & $0.63-24.57$ & 0.142 \\
\hline Yes &
\end{tabular}

Dissatisfaction: the amount paid for medications

\begin{tabular}{l|l|l|l}
\hline No & Ref & & \\
\hline Yes & 2.43 & $1.41-4.18$ & 0.002 \\
\hline
\end{tabular}

Dissatisfaction: the medications on formulary

\begin{tabular}{l|l|l|l}
\hline No & Ref & & \\
\hline Yes & 1.82 & $1.00-3.32$ & 0.051 \\
\hline
\end{tabular}

Dissatisfaction: find a pharmacy that accepted medication coverage

\begin{tabular}{l|l|l|l}
\hline No & Ref & & \\
\hline Yes & 2.88 & $0.57-14.63$ & 0.199 \\
\hline Cost-reducing behavior
\end{tabular}

Ever spent less on basic needs to save for medications

\begin{tabular}{l|l|l|l}
\hline No & Ref & & \\
\hline Yes & 2.23 & $1.21-4.10$ & 0.011 \\
\hline
\end{tabular}

$A D L=$ activities of daily living; $I A D L=$ instrumental activities of daily living; $O R=$ odds ratio; Ref $=$ reference group.

proportion of Medicare beneficiaries who are diagnosed with diabetes, ${ }^{26}$ underscores the need for effective diabetes prevention and management strategies to minimize the economic impact on those with diabetes. Initiatives, such as the National Diabetes Prevention Program and Diabetes Self-management Education and Support,,$^{27,28}$ help to achieve this goal by promoting a healthy lifestyle and better management of diabetes (eg, improving medication adherence). These and similar programs can potentially prevent or delay diabetes and its related complications, thereby reducing the financial burden associated with it. ${ }^{29-31}$

Health care professionals, such as physicians and pharmacists, also play a crucial role in the prevention and management of diabetes. For example, previous studies have shown that pharmacist involvement in diabetes care leads to significant improvement in medication adherence and overall glycemic control due to the provision of patient care services, such as education, medication reconciliation, and frequent follow-up. ${ }^{32}$ Reinforcement of healthy lifestyle choices and proper adherence by health care professionals leads to optimal health outcomes and ultimately lessens the financial burden on the patient. ${ }^{32}$

In addition to the implementation of prevention and management strategies, reevaluation of Medicare copayment structures to reduce OOP costs for beneficiaries would likely positively affect medication adherence. Colombi et al found that low copayments were associated with higher adherence to oral diabetes medications for individuals aged 65 years and older and for individuals under age 65 years. ${ }^{33}$ Maciejewski et al examined the effect of copayment reduction on adherence to medications for chronic diseases, such as diabetes, hypertension, hyperlipidemia, and congestive heart failure, and reported that a copayment reduction program, which eliminated generic medication copayments and reduced copayments for brand-name medications, improved medication adherence by $3.8 \%$ for those with diabetes. ${ }^{34}$

Finally, various cost-saving strategies can be used by health care professionals to minimize OOP costs for patients. Two major areas of potential cost savings are generic substitution (brand-name drug is replaced with its less expensive generic equivalent) or therapeutic substitution (an original medication is replaced with a less expensive substitute that is not bioequivalent but is clinically similar). Generic and therapeutic drug substitutions have been demonstrated to reduce annual OOP costs among Medicare Part D beneficiaries. ${ }^{35}$ Additional cost-saving strategies that can be implemented by health care professionals include providing resources to obtain low-cost drugs and linking patients with coverage programs.

Besides dissatisfaction with OOP costs, our study identified the act of spending less on basic needs, such as food and heat to save for medications, as another factor associated with medication nonadherence among Medicare beneficiaries with type 2 diabetes. This finding is consistent with previous work. ${ }^{4}$ Patel et al studied the US adult population aged 18 years and older with diabetes using 
the 2013 National Health Interview Survey and found that using costreducing strategies to compensate for expensive medications was associated with a higher likelihood of medication nonadherence. ${ }^{4}$ Although the degree of reduced spending on basic needs among beneficiaries is unclear, previous research has shown that food insecurity (which refers to "limited or uncertain availability of nutritionally adequate and safe foods or limited or uncertain ability to acquire acceptable foods in socially acceptable ways") was associated with medication nonadherence among older adults with diabetes. ${ }^{36}$

It is also well established that unmet food and medication needs could increase the risk of serious diabetes complications, further financially hindering the patient. ${ }^{37}$ Consequently, interventions such as supplemental food programs are an important component to ensure better medication adherence. Further research is needed to understand the magnitude of reduced spending on basic needs among beneficiaries and the consequences on medication nonadherence.

Other factors significantly associated with medication nonadherence were demographic characteristics, such as age and marital status. Younger beneficiaries reported significantly higher medication nonadherence than older beneficiaries, which corroborates previously published research. ${ }^{38}$ Moreover, we found that divorced/ separated beneficiaries to be less adherent to medication than married counterparts, providing further evidence that support from spouses or partners plays a crucial role in treatment adherence and glycemic control. ${ }^{39,40}$ We also observed that our study population of Medicare beneficiaries with type 2 diabetes had higher Medicare Advantage enrollment (or higher percentage of Medicare
Advantage prescription plan) than the general Medicare population, which is worth noting and warrants further investigation. These findings may be important when prioritizing resources to promote medication adherence in these at-risk populations.

Previous studies have used similar self-reported measures of skipping doses and/or taking smaller doses to measure medication nonadherence. ${ }^{20}$ To ensure the robustness of combining skipping doses and taking smaller doses to measure medication nonadherence, we also performed the analyses by using these 2 dependent variables separately. In general, the results from the 3 models were consistent for key variables of interest (Supplementary Table 2, available in online article).

\section{LIMITATIONS}

There are several possible limitations to this study. First, the population of interest in our study was communitydwelling Medicare beneficiaries aged 65 years and older with type 2 diabetes. Therefore, our results may not be generalizable to individuals who live in long-term care facilities, younger populations, or those with type 1 diabetes.

Second, since we did not have access to the claims data within the MCBS PUF, medication nonadherence levels were self-reported, which may have led to possible overestimation of adherence due to social desirability and recall biases, as most articles in the literature suggested. ${ }^{41-43}$ While a nonadherence analysis using claims data with the proportion of days covered and medication possession rate can measure refill behavior accurately, it does not necessarily reflect the real intake of medications or if medications were taken as prescribed. ${ }^{44}$ Self-reported nonadherence may be able to better capture nonadherence behavior, in which the medication was skipped or not taken as prescribed.

Furthermore, the adherence percentage for the current study may also be overestimated because beneficiaries in the adherence category may not have needed to take any medications at all, although this is unlikely, since our study population comprised those with type 2 diabetes.

Finally, the MCBS PUF is crosssectional, so a cause-and-effect relationship of the associated factors cannot be determined.

\section{Conclusions}

Dissatisfaction with the amount paid for medications and spending less on basic needs to save for medications were strongly associated with medication nonadherence. Our findings highlight the importance of greater engagement of various stakeholders to address this issue including physicians, pharmacists, social workers, and decision makers. Efforts to identify adherence barriers and provide guidance and services to manage prescription medication costs may help to improve adherence. Moreover, interventions to assist vulnerable groups who cut back on basic needs to save for their medications are recommended.

\section{DISCLOSURES}

No outside funding supported this study. The authors have no conflicts of interest to disclose.

\section{REFERENCES}

1. Centers for Disease Control and Prevention. Type 2 diabetes. May 30, 2019. Accessed May 25, 2020. https://www.cdc. gov/diabetes/basics/type2.html

2. American Diabetes Association. Economic costs of diabetes in the US in 2017. Diabetes Care. 2018;41(5):917-28. 
3. Hasche J, Ward C, Schluterman N. Diabetes occurrence, costs, and access to care among Medicare beneficiaries aged 65 years and over. Medicare Current Beneficiary Survey. Data Highlight. September 2017. Accessed April 30, 2021. https://www.cms.gov/research-statistics-data-and-systems/research/mcbs/ downloads/diabetes_databrief_2017.pdf

4. Patel MR, Piette JD, Resnicow K, Kowalski-Dobson T, Heisler M. Social determinants of health, cost-related nonadherence, and cost-reducing behaviors among adults with diabetes: findings from the National Health Interview Survey. Med Care. 2016;54(8):796.

5. Kang H, Lobo JM, Kim S, Sohn M-W. Cost-related medication non-adherence among US adults with diabetes. Diabetes Res Clin Pract. 2018;143:24-33.

6. Zhang JX, Lee JU, Meltzer DO. Risk factors for cost-related medication non-adherence among older patients with diabetes. World J Diabetes. 2014;5(6):945-50.

7. Kirkman MS, Rowan-Martin MT, Levin R, et al. Determinants of adherence to diabetes medications: findings from a large pharmacy claims database. Diabetes Care. 2015;38(4):604-09.

8. Yang Y, Thumula V, Pace PF, Banahan III BF, Wilkin NE, Lobb WB. Predictors of medication nonadherence among patients with diabetes in Medicare Part D programs: a retrospective cohort study. Clin Ther. 2009;31(10):2178-88.

9. Zhang JX, Meltzer DO. The high costrelated medication non-adherence rate among Medicare-Medicaid dual-eligible diabetes patients. J Health Med Econ. 2016;2(2):13.

10. Juarez DT, Tan C, Davis J, Mau M. Factors affecting sustained medication adherence and its impact on healthcare utilization in patients with diabetes. $\mathrm{J}$ Pharm Health Serv Res. 2013;4(2):89-94.

11. Americain Diabetes Association. Diabetes overview. Complications. Accessed May 25, 2020. https://www.diabetes.org/diabetes/complications
12. Gibson TB, Song X, Alemayehu B, et al. Cost sharing, adherence, and health outcomes in patients with diabetes. Am J Manag Care. 2010;16(8):589-600.

13. Centers for Disease Control and Prevention. National diabetes statistics report, 2020. Accessed April 30, 2021. https://www.cdc.gov/diabetes/pdfs/ data/statistics/national-diabetes-statistics-report.pdf

14. Centers for Medicare \& Medicaid Services. Medicare Diabetes Prevention Program (MDPP) expanded model. Fact sheet. November 2, 2016.

Accessed May 25, 2020. https://www. cms.gov/newsroom/fact-sheets/ medicare-diabetes-prevention-programmdpp-expanded-model\#_ftn1

15. Piette JD, Heisler M, Horne R, Alexander GC. A conceptually based approach to understanding chronically ill patients' responses to medication cost pressures. Soc Sci Med. 2006;62(4):846-57.

16. Zivin K, Ratliff S, Heisler MM, Langa KM, Piette JD. Factors influencing cost-related nonadherence to medication in older adults: a conceptually based approach. Value Health. 2010;13(4):338-45

17. Piette JD, Heisler M, Wagner TH. Problems paying out-of-pocket medication costs among older adults with diabetes. Diabetes Care. 2004;27(2):384-91.

18. Centers for Medicare \& Medicaid Services. Medicare Current Beneficiary Survey. Accessed June 23, 2019. https:// www.cms.gov/Research-StatisticsData-and-Systems/Files-for-Order/ LimitedDataSets/MCBS

19. Ciol MA, Hoffman JM, Dudgeon BJ, Shumway-Cook A, Yorkston KM, Chan L. Understanding the use of weights in the analysis of data from multistage surveys. Arch Phys Med Rehabil. 2006;87(2):299-303.

20. Madden JM, Graves AJ, Zhang F, et al. Cost-related medication nonadherence and spending on basic needs following implementation of Medicare Part D. JAMA. 2008;299(16):1922-28.
21. Stratton IM, Adler AI, Neil HAW, et al. Association of glycaemia with macrovascular and microvascular complications of type 2 diabetes (UKPDS 35): prospective observational study. BMJ. 2000;321(7258):405-12.

22. Ho PM, Rumsfeld JS, Masoudi FA, et al. Effect of medication nonadherence on hospitalization and mortality among patients with diabetes mellitus. Arch Intern Med. 2006;166(17):1836-41.

23. Ryan JG, Fedders M, Jennings T, Vittoria I, Yanes M. Clinical outcomes and incremental costs from a medication adherence pilot intervention targeting low-income patients with diabetes at risk of cost-related medication nonadherence. Clin Ther. 2014;36(12):1991-2002.

24. Rodbard HW, Green AJ, Fox KM, Grandy S, Group SS. Impact of type 2 diabetes mellitus on prescription medication burden and out-of-pocket healthcare expenses. Diabetes Res Clin Pract. 2010;87(3):360-65.

25. Luo J, Gellad WF. Origins of the crisis in insulin affordability and practical advice for clinicians on using human insulin. Curr Diab Rep. 2020;20(1):2.

26. Andes LJ, Li Y, Srinivasan M, Benoit SR, Gregg E, Rolka DB. Diabetes prevalence and incidence among Medicare beneficiaries-United States, 2001-2015. MMWR Morb Mortal Wkly Rep. 2019;68(43):961-66.

27. Centers for Disease Control and Prevention. What is the national DPP? Accessed July 16, 2020. https://www.cdc. gov/diabetes/prevention/what-is-dpp. $\underline{\text { htm }}$

28. Powers MA, Bardsley J, Cypress M, et al. Diabetes self-management education and support in type 2 diabetes: a joint position statement of the American Diabetes Association, the American Association of Diabetes Educators, and the Academy of Nutrition and Dietetics. Diabetes Educ. 2017;43(1):40-53. 
29. Gaillard T, Amponsah G, Osei K. Patient-centered community diabetes education program improves glycemic control in African-American patients with poorly controlled type 2 diabetes: importance of point of care metabolic measurements. J Natl Black Nurses Assoc. 2015;26(1):50-57.

30. Diabetes Prevention Program Research Group. Long-term effects of lifestyle intervention or metformin on diabetes development and microvascular complications over 15-year follow-up: the Diabetes Prevention Program Outcomes Study. Lancet Diabetes Endocrinol. 2015;3(11):866-75.

31. Sumamo E, Ha C, Korownyk C, Vandermeer B, Dryden DM. Lifestyle interventions for four conditions: type 2 diabetes, metabolic syndrome, breast cancer, and prostate cancer. AHRQ Technology Assessment Report. May 26, 2011. Accessed April 30, 2021. https:// www.cms.gov/Medicare/Coverage/ DeterminationProcess/downloads/ id82TA.pdf

32. Presley B, Groot W, Pavlova M. Pharmacy-led interventions to improve medication adherence among adults with diabetes: a systematic review and meta-analysis. Res Social Adm Pharm. 2019;15(9):1057-67.

33. Colombi AM, Yu-Isenberg K, Priest J. The effects of health plan copayments on adherence to oral diabetes medication and health resource utilization. J Occup Environ Med. 2008;50(5):535-41.
34. Maciejewski ML, Farley JF, Parker J, Wansink D. Copayment reductions generate greater medication adherence in targeted patients. Health Aff (Millwood). 2010;29(11):2002-08.

35. Duru OK, Ettner SL, Turk N, et al. Potential savings associated with drug substitution in Medicare Part D: the Translating Research into Action for Diabetes (TRIAD) study. J Gen Intern Med. 2014;29(1):230-36.

36. Afulani P, Herman D, ColemanJensen A, Harrison GG. Food Insecurity and health outcomes among older adults: the role of cost-related medication underuse. J Nutr Gerontol Geriatr. 2015;34(3):319-42.

37. Gucciardi E, Vahabi M, Norris N, Del Monte JP, Farnum C. The intersection between food insecurity and diabetes: a review. Curr Nutr Rep. 2014;3(4):324-32.

38. Chung GC, Marottoli RA, Cooney Jr LM, Rhee TG. Cost-related medication nonadherence among older adults: findings from a nationally representative sample. J Am Geriatr Soc. 2019;67(12):2463-73.

39. Rintala T-M, Jaatinen P, Paavilainen E, Åstedt-Kurki P. Interrelation between adult persons with diabetes and their family: a systematic review of the literature. J Fam Nurs. 2013;19(1):3-28.
40. Gonzalez-Zacarias AA, Mavarez-Martinez A, Arias-Morales CE, Stoicea N, Rogers B. Impact of demographic, socioeconomic, and psychological factors on glycemic selfmanagement in adults with type 2 diabetes mellitus. Front Public Health. 2016;4:195

41. Wagner GJ, Rabkin JG. Measuring medication adherence: are missed doses reported more accurately than perfect adherence? AIDS Care. 2000;12(4):405-08.

42. Stirratt MJ, Dunbar-Jacob J, Crane HM, et al. Self-report measures of medication adherence behavior: recommendations on optimal use. Transl Behav Med. 2015;5(4):470-82.

43. Rees G, Leong O, Crowston JG, Lamoureux EL. Intentional and unintentional nonadherence to ocular hypotensive treatment in patients with glaucoma. Ophthalmology. 2010;117(5):903-08.

44. Huber CA, Rapold R, Brüngger B, Reich O, Rosemann T. One-year adherence to oral antihyperglycemic medication and risk prediction of patient outcomes for adults with diabetes mellitus: an observational study. Medicine (Baltimore). 2016;95(26):e3994-e3994. 